Miami Nature Biotechnology Short Reports

TheScientificWorld (2001) 1 (S3), 132SR

ISSN 1532-2246; DOI 10.1100/tsw.2001.225

\title{
REGULATION OF LONGEVITY BY INSULIN/IGF-1 SIGNALING, SENSORY NEURONS AND THE GERMLINE IN THE NEMATODE C. ELEGANS
}

\author{
Cynthia Kenyon
}

Herbert Bayer Distinguished Professor of Biochemistry, University of California, 513 Parnassus

Avenue, San Francisco, CA 94143-0448

ckenyon@biochem.ucsf.edu

Aging is regulated hormonally in the nematode C. elegans. In my presentation, I will describe this elaborate endocrine system, which involves an insuln/IGF-1 signaling pathway, with inputs from the sensory tissues and the reproductive system. Our studies suggest that multiple hormones regulate the life span of this animal, including insulin/IGF-1-like hormones and a steroid hormone. Aging in this organism is extremely plastic; changes in any of a number of genes can extend youthfulness and double, or even quadruple, life span. 


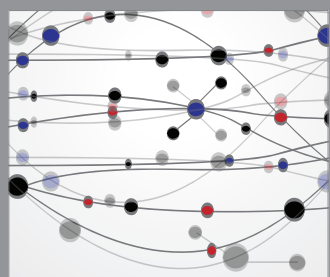

The Scientific World Journal
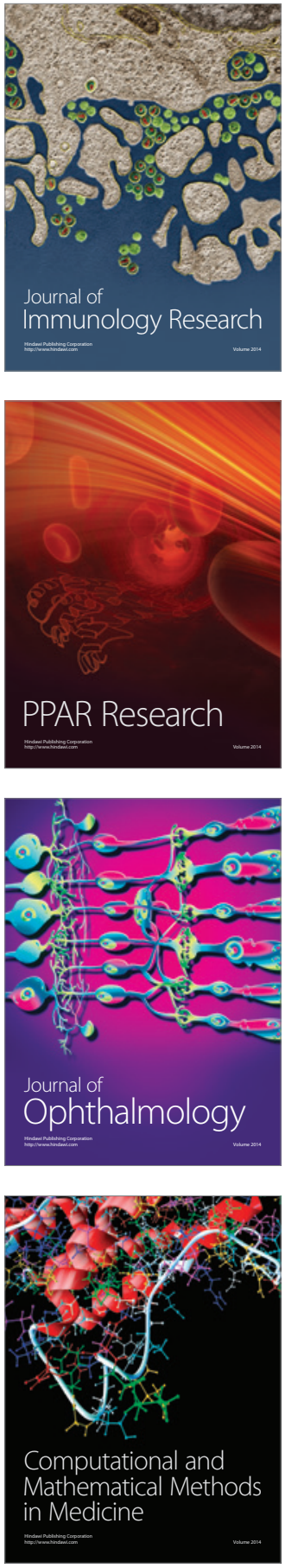

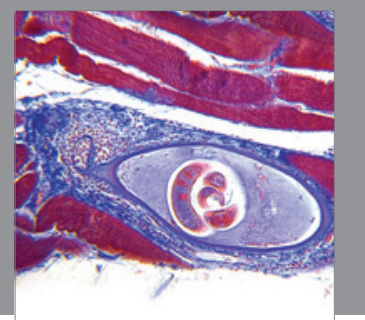

Gastroenterology

Research and Practice
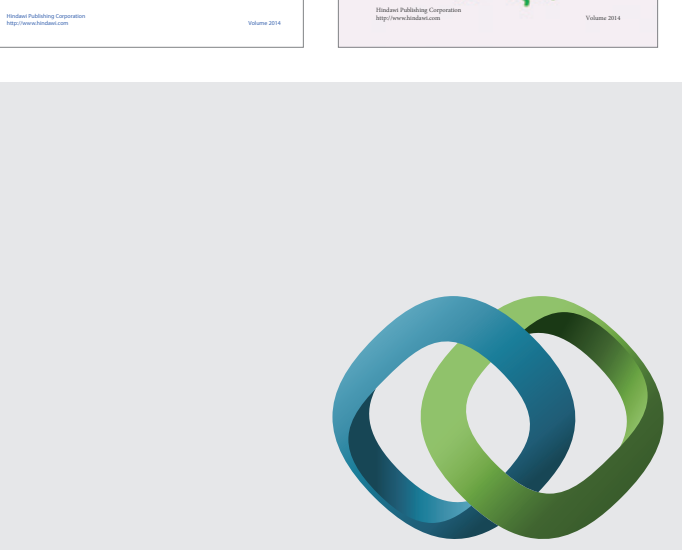

\section{Hindawi}

Submit your manuscripts at

http://www.hindawi.com
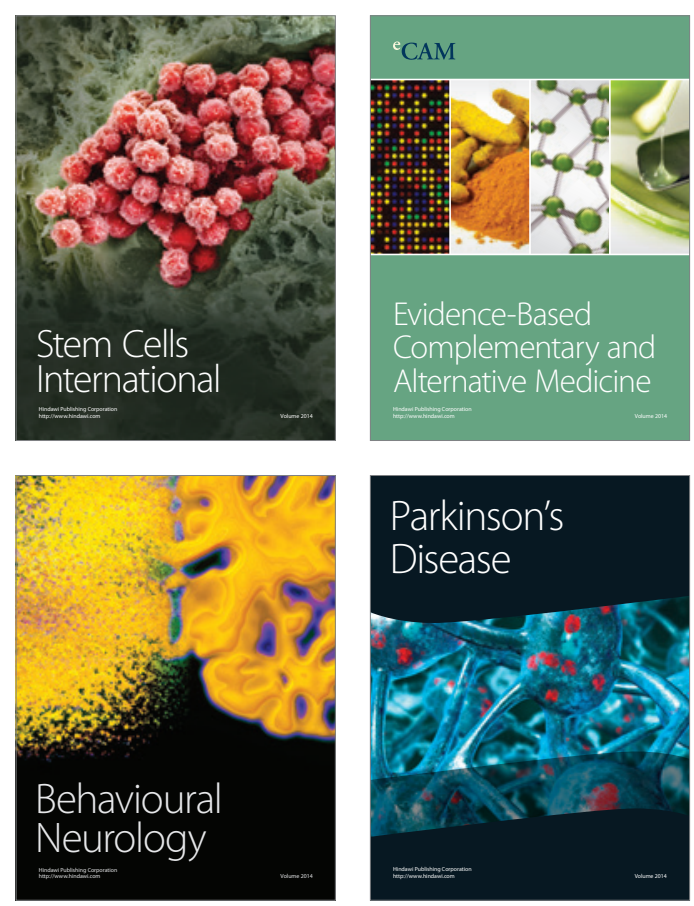

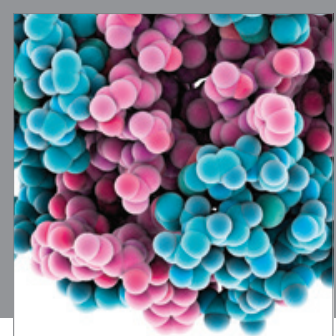

Journal of
Diabetes Research

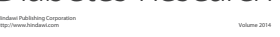

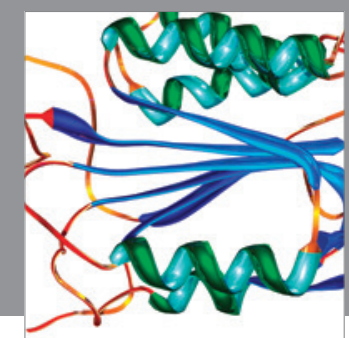

Disease Markers
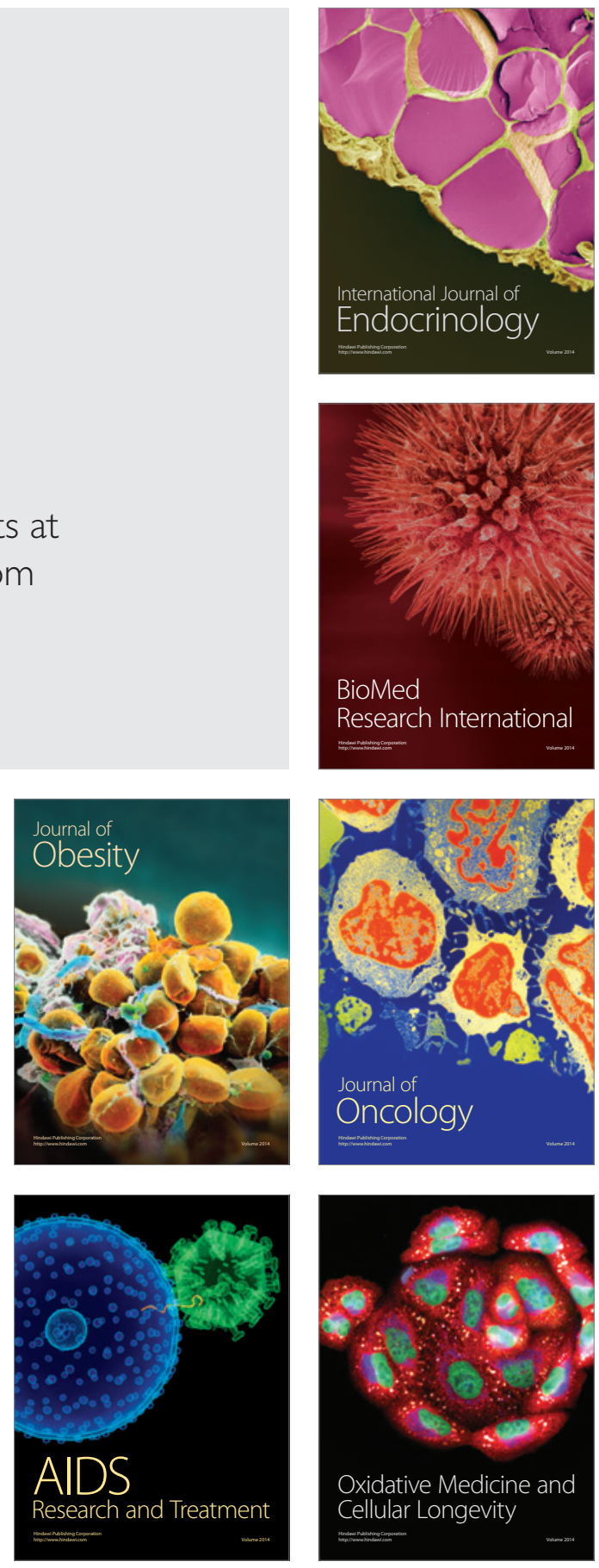